\title{
TOWARDS AN OPERATIONAL CONCEPT OF SUSTAINABLE MOBILITY
}

\author{
D. HOYOS \\ Environmental Economics Unit, University of the Basque Country, Spain.
}

\section{ABSTRACT}

The magnitude of the social and environmental costs owed to transport in the European Union (EU) has shown the urgent need to introduce measures for the internalization of externalities and to advance, this way, towards a more efficient transport system. The growing development of the theory of externalities and the most efficient instruments for its internalization have contributed to the introduction of road transport charges in some countries like Switzerland, Austria or Germany. In spite of this, the infrastructure pricing seems insufficient to cut off urgent environmental problems such as climate change and the depletion of natural resources. Taking the limitations of the conventional transport policy as a starting point, this article aims to advance an operative definition of the concept of sustainable mobility, and to set a framework capable of assuring that sustainable mobility becomes a useful and efficient tool for transport policy in the 21 st century. In this context, instruments that traditionally were out of transport policy, such as land use or urban planning, acquire great importance. The Basque Country, a region in the western Pyrenees Mountains that spans the border between France and Spain, will be used as an example because of sharing with many regions of the EU similar transport and environmental problems.

Keywords: externalities, internalization, sustainability, sustainable mobility, transport policy.

\section{INTRODUCTION}

The changes that are taking place in the way we understand the current development model - under the broad notion of sustainable development - are slowly affecting the way we see the transport system due to the fact that, if on the one hand it constitutes a fundamental support in social and economic development, its most recent evolution seems to show symptoms of hypertrophy. The enormous growth of transport for the last decades has been accompanied by a considerable socioenvironmental cost: human health and environmental damages, risk of traffic accidents and growing road congestion. In monetary terms, the annual external costs of transport in the European Union (EU)-17 (EU-15 member states plus Switzerland and Norway) have been estimated at 650 billion $€$ for 2000, accounting for 7.3\% of its gross domestic product (GDP) [1]. Public institutions are thus facing a double-edged sword since feeding the mobility wished by people multiplies its adverse environmental and socio-economic effects.

Transport economics tends to search for solutions for the aforementioned problems within the transport system itself, considering the optimal infrastructure pricing the most efficient tool for the internalization of externalities. However, just as the European Commission [2] points out, 'the "transport dilemma" consists of a series of inter-related problems requiring an integrated response'. Clearly, transport efficiency constitutes an evident objective of the transport system, yet, as we shall see, it is neither the only objective nor the most important.

A decade after the European Commission started to work towards a more efficient transport pricing system, the progress achieved on this matter has been scarce, mainly due to the reluctance of some member states. The modification of the current 'Eurovignette' Directive [3] does not seem to be improving this situation, given that it does not consider the inclusion of environmental costs in the future pricing framework of the Union. Nevertheless, this state of affairs has not prevented countries like Switzerland (2001), Austria (2004) or Germany (2005) from introducing heavy goods 
vehicles charges successfully, based on the distance covered on their main roads or other countries like Great Britain, Czech Republic, Slovakia and Hungary from considering similar measures. In addition, the introduction of central London's area charge encouraged other European cities like Stockholm or Milan to do likewise.

The 'sustainability' concept has extended rapidly to all political spheres in spite of the fact that, rather than creating profound changes, in most cases, it has only served as a new label for the same old policies. As a result of this, sustainable mobility and sustainable transport are terms that appear more frequently in the political discourse even though, in practical terms, new policies are not too different from the previous ones.

The purpose of this article is to attain an operational definition of the concept of sustainable mobility. It also aims to establish the basis, so sustainable mobility, instead of being a void political goal, turns into a useful and effective instrument for transport policy in the 21st century. For this purpose, the following section reviews the scope and limitations of the conventional instruments for the internalization of externalities. The limitations of the conventional framework to cut off the current environmental crisis is the starting point to reconsider, in section three, the objectives for the internalization of externalities on the basis of the sustainability concept. In section 4, the Basque Country stands as case study at a European regional level to show empirically the limitations from a sustainability perspective inherent to the conventional framework of transport policy. Finally, section five provides some conclusions and political implications.

\section{CONVENTIONAL TRANSPORT POLICY: SCOPE AND SHORTCOMINGS}

Under the assumption that mobility and speed are good for their own sake, transport policy has traditionally focussed on the offer of new infrastructures as the only instrument to cope with the growing need of mobility. However, the confirmation that traffic congestion is not solved and that, additionally, it is aggravated by the increase of the infrastructure offer and a greater public awareness regarding the environmental and social effects of transport has led the traditional transport policy to search for other instruments to reduce the socio-environmental and economic costs of transport, in what is known as the internalization of externalities. Currently, there are few doubts regarding the fact that the offer of new infrastructures reduces the congestion punctually and in the short term, but worsens the global problem in the long term $[4,5]$.

The need of urgent public intervention is beyond any doubt: the external costs of transport have doubled since the European Commission [2], one decade ago, pointed out that 'the amount of total costs is so great that governmental intervention is definitely necessary'. External costs of transport in Western Europe have been estimated for 1990, 1995 and 2000 [1, 6, 7]. More recently and using the same methodology, external costs of transport have also been estimated for Eastern Europe [8].

It is widely accepted that the price signs of current transport markets do not show actual costs, which entails an excessive demand and a structural distortion of such sector [9]. Within the framework of neoclassical economics, this situation is explained by the inefficiency of the market device in the presence of externalities. The analysis of externalities is based on the loss of social welfare derived from some market prices that do not illustrate accurately the resource scarcity (clean air, noise, etc.). Once internalized (i.e. incorporated to the analysis), the market ensures the efficient allocation of the resources. All in all, the purpose of internalizing the externalities is no other than reducing the inefficiency of the transport system, i.e. reducing the area that separates private costs and marginal social costs.

Although internalization is usually related to pricing (i.e. with the incorporation of external costs to transport prices), the internalization of externalities includes a wide range of instruments. The instruments to internalize externalities compiled in Table 1 are divided in four groups depending on 
the level of public intervention: 'soft' measures in the upper part and 'hard' measures in the lower part. Information and education measures aim to increase knowledge on the impact of the economic activity within the environment to act on the behaviour patterns while they make possible the political acceptability of environment protection measures. On the other hand, the economic instruments, based on the polluter pays principle, seek that prices to reflect real costs (including external costs), either through the regulation of prices (positive or negative incentives aimed to correct the market system) or quantities (property rights trading). Thirdly, regulation instruments establish technical standards or rational demands. Some examples are the pollutant emission standards, speed limits, entrance prohibition to a certain area, etc. Lastly, the most direct measure to intervene in the transport market is to act on the infrastructure offer, which is an exclusive competence of the public institutions.

The economic instruments are based on the idea that market device guarantees an efficient allocation of resources. Even though economic incentives can regulate quantities or prices, price signs are usually seen as the most adequate way to correct the market's inefficiencies. According to the Commission [2], 'individuals choose their mode of transport, their location and investments based, basically, on the prices. Therefore, for transport to be appropriate, prices must also be appropriate'. The idea behind these measures is that transport taxes are far from covering the externalities generated by it and, therefore, external costs must be included in the prices, by means of purchase or vehicle circulation taxes, fuel taxes, parking fares, infrastructure charging, etc. Additionally, the current tax scheme does not allow distinguishing the effects produced by different vehicles and uses: polluting emissions of more or less powerful vehicles, urban or non-urban destinations, rush hour or non-peak hour journeys, etc. However, it is important to bear in mind the limitations that pricing policies have due to the fact that individuals may base their decisions not only on prices but also on a rather generalized cost framework including other factors such as waiting time or comfort of the transport mode.

Table 1: Policy instruments for internalizing external effects [6].

\begin{tabular}{|c|c|c|}
\hline \multicolumn{2}{|c|}{ Instruments } & \multirow{2}{*}{$\begin{array}{l}\text { Examples } \\
\begin{array}{l}\text { Voluntary agreements with } \\
\text { industry }\end{array}\end{array}$} \\
\hline $\begin{array}{l}\text { Information and moral } \\
\text { persuasion }\end{array}$ & $\begin{array}{l}\text { Information on facts and } \\
\text { interdependencies } \\
\text { Social marketing of public } \\
\text { programmes }\end{array}$ & \\
\hline Economic incentives & Price regulation & $\begin{array}{l}\text { Negative incentives (fares, } \\
\text { charging per emissions, etc.) } \\
\text { Positive incentives (aids, } \\
\text { loans, etc.) }\end{array}$ \\
\hline & Quantity regulation & $\begin{array}{l}\text { Trade of property rights } \\
\text { (emissions, energy) }\end{array}$ \\
\hline Regulatory instruments & Regulations, decrees & $\begin{array}{l}\text { Emission standards } \\
\text { Specification of processes or } \\
\text { products } \\
\text { Institutional regulation, etc. }\end{array}$ \\
\hline $\begin{array}{l}\text { Infrastructures and services } \\
\text { provided by the public sector }\end{array}$ & $\begin{array}{l}\text { Construction and maintenance } \\
\text { of transport systems }\end{array}$ & $\begin{array}{l}\text { Roads, railways, ports and } \\
\text { airports }\end{array}$ \\
\hline
\end{tabular}


Among price measures, the use of economic incentives through pricing systems, this is, payment for the use of transport infrastructures or road pricing, has been increasingly accepted and developed in specialized literature. Although there are numerous strategies applicable to infrastructure pricing (charging based on marginal costs, pricing according to the average cost, Ramsey pricing rule, price discrimination, etc.), road pricing at the marginal social cost is the most efficient internalization instrument (i.e. it is the instrument that theoretically fulfils this objective at the minimum cost). As a consequence, it represents the starting point of the Community's policy on a fair and efficient pricing on transport [10], as well as one of the main lines of the Community's policy as far as transportation towards 2010 is concerned [11].

Following the principles of neoclassical economic theory, pricing at marginal cost is the most efficient instrument, given that the consumer's surplus is maximized: prices above the marginal cost would prevent journeys with a social value over the cost of performance, while prices below the marginal cost would promote journeys with a cost above their marginal benefits for the society. The principle of efficient pricing considers that users should be charged with short-term marginal social costs. Bearing in mind the difficulties of this principle to recover the investment costs, some authors defend pricing at the long-term marginal cost, which would allow an optimal adjustment of capital stock and, consequently, adjusting the infrastructures' capacity to the traffic. Nevertheless, since the capacity is not usually the most favourable (if it were both values would be equivalent), it is preferable to use pricing to achieve an optimal use of the existing infrastructure and to use methods of investment analysis to adjust the capital stock [12].

In spite of being a simple principle, the implementation of optimal prices is more complicated. In practice, the fixation of transport prices faces several difficulties, so they can be equivalent to the marginal social cost. Thus, the difficulty of estimating the marginal cost (variable depending on the vehicle, hour, place, etc.); the market structure, which usually has few operators; and the fact that equity or political acceptance might be more decisive elements than efficiency concerning price fixing have been emphasized [13]. Additionally, there are other added obstacles, such as the interrelation between the different modes of transport, given that it is necessary (and extremely complicated) to determine optimal prices simultaneously for every transport market, the fact that space planning is decisive for the long-term growth of mobility and the existence of imperfections in the economy [14]. In this regard, the economic theory is clear when it states that pricing at the marginal social cost in one sector can only be good if this criterion covers the other sectors, meanwhile current economy is characterized by the existence of price distortions and market imbalances.

Equally controversial is the use of the revenues generated in an infrastructure pricing scheme, given that the desirability and social acceptability of such measures depend essentially on the reallocation of the revenues collected. In this regard, the public acceptability of infrastructure pricing depends on the existence of a wide agreement between the agents involved, the use of the earnings to reduce the transport externalities that have justified the introduction of this measure and the granting of attractive and fair transport alternatives [15]. Additionally, it is important to bear in mind that limiting the use of revenues to transport might generate an excessive investment, which may tend to start a project of uncertain social profitability [16]. In any case, acceptability keeps being an issue to be resolved; therefore, it is being investigated by the EU within the project REVENUE [17].

The growing empirical evidence of the effects of infrastructure pricing on the internalization of transport externalities can contribute to clear up some doubts. An empirical study on the intercity transportation of goods carried out in Belgium concluded that road pricing was effective concerning the limitation of road congestion, pollution, accidents, noise and infrastructure damage [18]. However, other researches proved to be considerably less optimistic: 'the simple belief that a move to a 
more efficient pricing would uniformly benefit the more environmentally friendly modes at the expense of other modes is also found to be not universally true' [19]. According to the results obtained in the European project PETS, although efficient pricing would entail an enormous modal transference to train and bus in urban areas (transport by car would be reduced to approximately $32 \%$ and bus and train would increase around 23 and $30 \%$ respectively) improving local environmental problems, the effects on modal allocation and environmental problems outside urban areas would be minimum [12]. Additionally, given that the traffic in the city is a relatively small part of the total traffic, its contribution to fight climate change would be insignificant. Other European studies, such as project TRENEN II STRAN, reached similar results: the best fees reduced the volume of transport in urban areas between $7 \%$ and $14 \%$ (between $2 \%$ and $3 \%$ in rural areas), while the external costs were reduced between $13 \%$ and 35\% in the first case and between 3\% and 5\% in the second [14]. Finally, the implementation of the heavy vehicle fee in Switzerland had a discreet effect on pollutant emissions and modal allocation, so the on-time fulfilment of the environmental objectives is considered 'optimistic' [20].

By verifying that economically efficient prices will only have a positive impact on the transport emissions at a limited range of transport backgrounds [14], these authors divide the externalities in two groups (the ones exclusively determined by vehicle volume, e.g. congestion, and the ones determined by other factors, e.g. air pollution). This division helps to explain that the most appropriate internalization instrument depends on the externality considered: although in the first case pricing during rush hours could be more appropriate, in the second case, technological measures, such as the introduction of catalysers, could be chosen.

This way, it is confirmed that reaching a balance between a series of objectives (social, environmental, etc.) is very complicated by means of just one internalization instrument [21]. Furthermore, the Organisation for Economic Co-operation and Development (OECD) [22] notes that 'in some cases, the implementation of instruments separately can have negative effects'. In this sense, it is important to point out that the Community's commitment to pricing complements (and does not substitute) the direct regulating action. In other words, the Commission does not leave the solution to every problem in the hands of the establishment of a fair and efficient pricing system, but it considers it as a way to accompany the regulatory measures in force [2].

Thus, instead of reducing the accomplishment of several objectives to the implementation of just one instrument, it might be more appropriate to difference the instruments depending on the externality to be faced [23]. The management of the demand and the information systems is very useful against congestion, although rush hour pricing is considered the most efficient instrument. With regard to traffic accidents, they are committed to educational measures, insurance estimation modifications or speed limits. Air pollution and climate change would require technological measures and fuel or distance taxation. Lastly, other externalities such as effects on biodiversity and landscape could be reduced by means of taxes based on compensation or preventive measures. Table 2 includes different instruments depending on the externality considered.

\section{SUSTAINABILITY AND SUSTAINABLE MOBILITY, A TRANSDISCIPLINARY APPROACH}

Traditional transport policy tends to tackle transport problems from within, avoiding the existence of exogenous elements with notable implications on mobility. As a result of such apparent short sight, the measures reviewed in the previous section are focussed on transport solutions for transport problems. This approach, far from questioning the nature of journeys, just rationalizes them for an optimal use of the existing infrastructures. Nevertheless, in order to be sustainable, the transport system must not only be efficient but also accomplish even more important objectives, such as 
Table 2: Cost effectiveness of internalization instruments [8].

\begin{tabular}{|c|c|c|c|}
\hline & $\begin{array}{l}\text { Type of } \\
\text { instrument }\end{array}$ & Effectiveness & $\begin{array}{l}\text { Cost } \\
\text { effectiveness } \\
\text { ratio ranking }\end{array}$ \\
\hline \multicolumn{4}{|l|}{ Congestion } \\
\hline Rush hour fee & Economic & High & 1 \\
\hline $\begin{array}{l}\text { Telematic instruments for infrastructure } \\
\text { management } \\
\text { Accidents }\end{array}$ & Technical & High & 2 \\
\hline Education & Institutional & Medium & 1 \\
\hline $\begin{array}{l}\text { Modification of insurance estimations } \\
\text { (bonus-malus) }\end{array}$ & Economic & High & 2 \\
\hline Blood alcohol level limits & Regulation & High & 3 \\
\hline Speed limits & Regulation & Very high & 4 \\
\hline Driving lessons & Institutional & High & 5 \\
\hline Local measures & Infrastructure & Locally high & 6 \\
\hline \multicolumn{4}{|l|}{ Noise } \\
\hline New braking systems for trains & Technical & High & 1 \\
\hline Reduction of engine noises by heavy vehicles & Technical & Low & 2 \\
\hline Speed limits & Regulation & Medium & 3 \\
\hline Special tyres for the road & Technical & Low & 4 \\
\hline Sound panels & Infrastructure & High & 5 \\
\hline \multicolumn{4}{|l|}{ Air pollution } \\
\hline Alternative bus engines & Technical & Low & 1 \\
\hline Engine standard EURO III and IV & Regulation & High & 2 \\
\hline Fees per Km (depending on the emissions) & Economic & High & 3 \\
\hline Fuel taxation & Economic & High & 4 \\
\hline Urban parking price policy & Economic & Medium & 5 \\
\hline Urban tolls & Economic & Medium & 6 \\
\hline Traffic calming measures & Regulation & High & 7 \\
\hline Speed limits & Regulation & Medium & 8 \\
\hline \multicolumn{4}{|l|}{ Climate change } \\
\hline Driving courses & Institutional & Medium & 1 \\
\hline Fuel taxation & Economic & High & 2 \\
\hline Alternative fuels & Technical & High & 3 \\
\hline Feebate roads & Economic & Low & 4 \\
\hline Fuel standards & Regulation & Medium & 5 \\
\hline Speed limits & Regulation & Medium & 6 \\
\hline
\end{tabular}

Ranking order: 1 = measures with best cost-effectiveness ratio. 
effectiveness and sufficiency, long-term approach, practical implementation and transparency or the consideration of especially sensitive areas [7].

Deepening into the concept of sustainability obliges us to understand that transport requires a systemic approach, able to provide an answer for multiple variables and objectives. In this section, we will see how sustainable mobility is configured as the only future framework able to undertake socio-economic and environmental problems derived from the current mobility patterns, some of them being increasingly urgent, such as climate change or the depletion of non-renewable resources such as oil. Previously, however, it is necessary to go deeper into the concepts of mobility and sustainability in order to achieve, in a second part, an operational definition of the sustainable mobility concept.

Transport demand is a product of the social, cultural, territorial and economic model. Transport is part of the mobility, the materialization of actual movement. Nevertheless, the concept of mobility does not only enclose actual movement but also a potential mobility expressed, from the offer side, through the maximum capacity of the existing infrastructures and, from the demand side, through the wishes or needs of mobility. All in all, socio-economic factors comprising the mobility wishes or needs put on the pressure to turn such potential mobility into actual movement, into transport [24].

This analysis allows us to understand that the need of mobility can be satisfied, not only by increasing the infrastructure offer but also adjusting the offer and the demand in a better way, or by reducing the pressure of the mobility demand. The first option constitutes the main line of the traditional transport policy, the continuous expansion of the infrastructure offer. The second option would be framed within the new policies discussed in the previous section, which intend to improve the efficiency of the transport system by means of demand management policies (pricing, public transport promotion, shared vehicles, etc.). OECD's work [25] is a basic referent as far as demand management policies are concerned. The last option is going to be the source of the problem to find devices capable of reducing the demand pressure, i.e. minimize the mobility, making accessibility possible instead of the transport. This tool, in spite of receiving the less attention, is the basis for the transition towards transport sustainability.

From an ecological perspective, sustainability may be understood as the capacity of the economic system to adapt to the natural environment [26]. In other words, the sustainability concept questions the physical feasibility of the current development model throughout time. Consequently, the durability of the system imposes natural limits, determined by the preservation of the biological diversity and the availability of natural resources and ecological services. The sustainability has, therefore, an intra- and intergenerational component: the size of the current environmental problems will affect the resources and the quality of life of present and future generations. This definition involves notorious implications for transport, both regarding pollutant emissions (with special regard to climate change fight) and the depletion of scarce resources, such as petroleum or land. In fact, the OECD defines sustainable transport as the one that 'does not endanger public health or ecosystems and meets mobility needs which are consistent with the use of renewable resources below their rates of regeneration and the use of non-renewable resources below the rates of development of renewable substitutes' [22].

By joining the concepts of mobility and sustainability, we can understand sustainable mobility as a process that tends to reduce the irreversible environmental degradation of the current transport model while it satisfies the social need of accessibility. This definition encloses several key issues belonging to sustainable mobility: (1) environment is an essential part of the development process; (2) sustainable mobility, more than a static representation, is a process (i.e. it requires permanent actions and not single solutions); (3) sustainable mobility cannot be defined without a greater background of sustainable development; (4) reducing the irreversible environmental degradation involves 
the use of mainly renewable resources; (5) transport is the mean (and not an end) to meet the needs (and not the wishes); and, finally, (6) political action must insist on providing accessibility and not transport, i.e. pursuing the satisfaction of necessities favouring their proximity, instead of feeding the number and length of movements.

To make certain that the social access demand does not exceed the environmental limits, it is required a turnaround concerning public policies directed to the achievement of three goals: reducing the need of transport, rebalancing the modal allocation in favour of more environmentally friendly modes of transport (conventional train, ship, bicycle, walking) and improving the eco-efficiency in trips. The accomplishment of these goals requests a systemic approach, capable of designing strategies conceived from a holistic and cross-disciplinary view, in which all policies with effects on mobility (land planning, urban planning, industrial and energy policy, etc.) participate integrally with special interest on the source of the problems. Additionally, the awareness of the citizens, the enterprises and the institutions to change the behaviour regarding transport and life style (transport demand, land planning, etc.), as well as an active social participation in the design of these policies, are necessary.

On the whole, the creation of proximity must outline the fundamental line of a sustainable mobility policy. Under this perspective, the instruments addressed to reduce the necessity of travelling gain importance, this is: a land planning that limits private vehicle mobility (preventing urban sprawl, stopping the growth of shopping centres and industrial areas that can only be reached by car, etc); an urban planning that reduces the use of land (compact urban models, traffic calming measures, streets for pedestrians, localization of activities and services based on mixed uses, etc.); promotion of public transport (greater offer of services, special road tracks, etc.); re-evaluation of current production, distribution and consumption patterns and citizen awareness and education to adopt new life styles. Furthermore, given the close relation between ownership and use, reducing private vehicle ownership may be considered as an explicit objective of the sustainable mobility policy, through the promotion of vehicle renting, car sharing, home delivery systems, etc. [27]. Moreover, these measures do not only favour the fulfilment of environmental objectives, but they also contribute to grant greater efficiency to the transport system by reducing the pressure of the mobility demand; therefore, far from being substitutes, they are considered complementary to the measures displayed in the previous section. Thus, for instance, road pricing schemes may contribute to increase the capacity of cities and prevent urban sprawl [14, 28].

Finally, it is important to stand out that the nearly total dependency of road transportation on fossil fuels, mainly petroleum, turns transport into an easy prey for the progressive increase of fuel prices. Although the issue seems to have passed unnoticed among transport economists, the proximity of the peak-oil would have serious consequences on the economy in general, but specially on the transport sector, as energy represents the significant amount of 32\% of road transportation costs [29]. The 'end of cheap oil era', as several experts named it, represents not only a substantial change in the energy model but also the break of the predominant paradigm, which will have to speed up its transition to sustainability [26]. This situation goes deeper into the need for sustainability to constitute the main line of the future transport policy within the terms and scope covered in this section.

\section{CASE STUDY: THE BASQUE COUNTRY}

The autonomous community of the Basque Country is a Spanish region located in the western Pyrenees that includes three provinces: Alava, capital Vitoria-Gasteiz; Biscay, capital Bilbao and Gipuzkoa, capital Donostia-San Sebastian (Fig. 1). With 2,133,684 inhabitants and 7.234km², its population density $\left(295 \mathrm{hab} / \mathrm{km}^{2}\right)$ is the second highest in Spain after Madrid. In 2006, the Basque Country's GDP accounted for 61 billion $€$. Per capita income at PPP situates the Basque Country at 


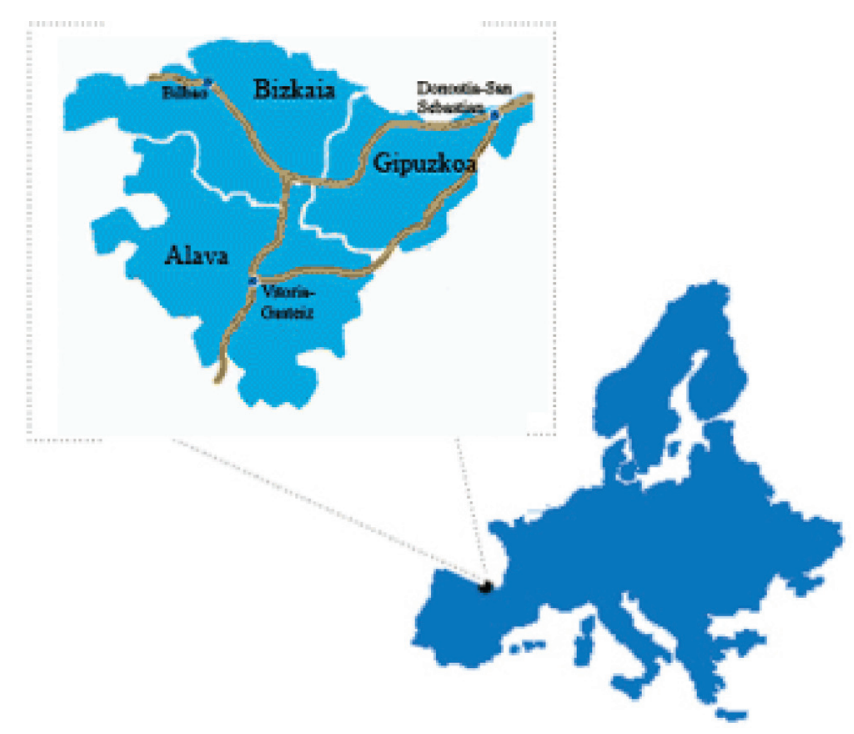

Figure 1: Basque Country in Europe, location map.

EU-15 average levels. The Basque Country's economic structure is dominated by services (59.4\%), although the industrial sector is relatively high (25.8\% of GDP as compared to Spanish average of $10.8 \%$ ). Construction accounts for $10.2 \%$, energy for $3.3 \%$ and agriculture for $1.3 \%$. Finally, unemployment rate was of $6.1 \%$ in 2007 [30].

The analysis of the Basque economy's metabolism shows immediately the outstanding influence of transport on the unsustainability of the current development model. Even though the territorial configuration is, to a great extent, determined by the transport system, when it is governed by freight road transport and the massive use of private vehicles for the transport of people, the related socioenvironmental and economic problems grow considerably: increase of the natural resources consumption (mainly land and energy), emission of contaminants, climate change, noise levels, accidents, reduction of public space, insecurity, etc. Thus, the hegemony of road transport and the exceptional growth of air transportation in the last years (the most inefficient modes of transport, huge resource consumers and with greater environmental impact) have multiplied environmental, social and economic impacts of transport. To a relative extent, this picture may well describe many European regions' current situation, although using a smaller geographical context may facilitate the analysis. That is mainly the reason why in this section the Basque Country will be presented as a case study. It will, therefore, help to illustrate the limitations of the conventional transport policy framework as well as the urgent need for a transition to sustainable mobility policies.

\subsection{Basic data}

As mentioned before, the Basque inland modal share is greatly dominated by road transport, which is used to carry $73 \%$ of the goods and $85 \%$ of the people (percentages based on passenger-km and tonnes-km). Rail transport, instead, is responsible for the transport of $2 \%$ of the goods and $8 \%$ of the people. Finally, sea transport takes care of $30 \%$ of all goods, while air transport is used to carry $1 \%$ of the people [31]. While sea and railway carriage of goods have been more or less static between 
1990 and 2004, road transport has increased four times the volume of goods transported, from 25 to over 100 million tons [29]. The existing modal share is similar to that in the EU in 2005: the modal split of passenger transport (pass-km) is very similar (82\% road, $7 \%$ rail and $1 \%$ plane) and the modal split for inland freight transport (ton-km) has more presence of rail (73\% road, 16\% rail) [32].

The spectacular growth of transport in the Basque Country in the last years is caused by multiple factors, although two of them may be highlighted: economic growth and increase of the demand of mobility. The volume of carriage of goods by road is growing at a higher rate than the economy, which is making more difficult to comply with the European objective of decoupling economic and transport growth. Between 1990 and 2004, while economy grew by 50\%, the volume of carried goods grew by $314 \%$.

In turn, the increase of the mobility demand is caused by different factors. Firstly, there is a close relation between the per capita income, the levels of motorization and road traffic, as Fig. 2 shows. Thus, between 1990 and 2003, the car fleet of the Basque Country increased by 50\% (at a 3\% annual rate), reaching 450 vehicles per 1,000 inhabitants (EU-15 average was 503 passenger cars per 1000 inhabitants in 2005 [33]. Road traffic on the A-8 (the main road in the region, see Fig. 1) has increased by $77 \%$.

Secondly, the growth of low-density urban settings increases the use of private vehicles, which entails: high consumption of natural and energetic resources, economic and material difficulties to provide public transport, increase of road traffic congestion and the construction of new road and services infrastructures (sewing system, electricity, etc.) [35]. Between 1991 and 2001, the number of single-family households in the Basque Country increased by $16 \% ; 9,720$ units [30]. As a result of the growth of low-density urban settings, we are facing higher levels of motorization and a decrease in vehicle occupation. Between 1989 and 1999, the number of families owning more than one car shifted from $8 \%$ to $20 \%$, meanwhile, the occupation rate has decreased from 1.53 passengers per vehicle in 1990, to 1.49 in 1995 and to 1.35 in 2001 [36].

The proliferation of shopping centres is related to the above-mentioned scenario. The Basque Country currently has 28 shopping centres, and it is the second region in Spain in terms of density with such centres. Only in the province of Biscay, 12 shopping centres were built between 1986 and 2003, with almost 18,000 parking lots, which means an average of 67,000 more private vehicle trips every day [37].

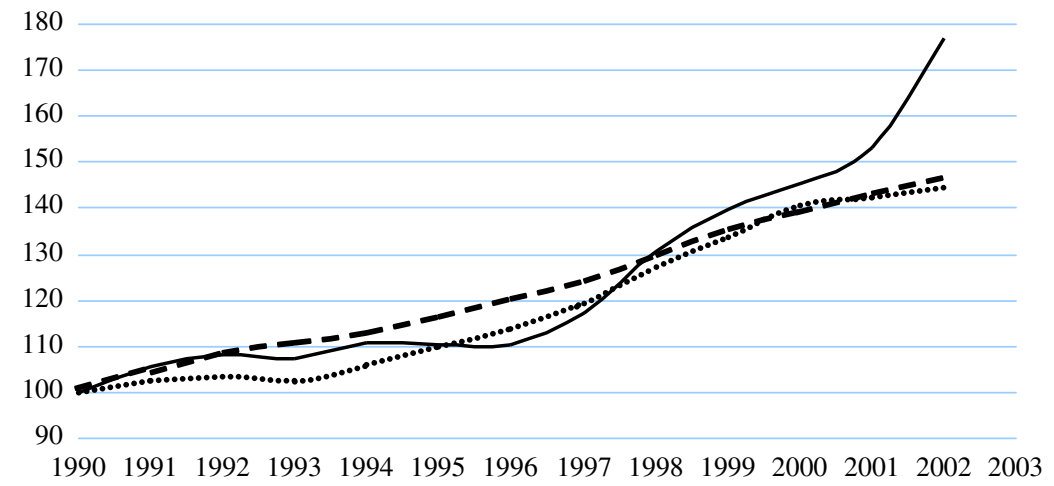

$$
\text { ...... Per Capita Income - - Car Fleet } \quad \text { A-8 Traffic }
$$

Figure 2: Per capita income, vehicles and traffic. Base $1990=100$ (self-elaboration based on data from [34]). 
Public investment is the last factor to consider in order to explain the increase of road transport in the Basque Country. Therefore, public investment in transport infrastructures since 1990 has exceeded 4,500 million $€$, mainly for the maintenance and construction of the road network (70\%), a much greater share than that for rail transport (14\%), sea transport (13\%) and air transport (3\%) [28].

\subsection{Environmental and socio-economic consequences}

In spite of the great efforts carried out by public institutions to provide new transport infrastructures, traffic congestion on the Basque roads increases every year. In practice, the construction of new infrastructures has been insufficient to cope with the growing demands of road users. As a result of this, the ratio of infrastructures per vehicle has decreased steadily throughout this last decade and, with it, traffic and road congestion has grown exponentially. Traffic in the Basque highways is increasing at rates over $5 \%$ (11\% in the province of Gipuzkoa), with the percentage of heavy vehicles reaching $20 \%$ of the total traffic [37-39]. Congestion shows the permanent delay in the offer of infrastructures, compared with the mobility demand; such delay is chronic due to the financial and political problems that public institutions must face when constructing new road infrastructures. Far from reaching a solution, traffic congestion gets worse every year due to some of the factors mentioned in the previous subsection: high population density, increase of motorization levels, cheaper relative cost of vehicle ownership, higher number of families with their own vehicle, higher number and longer distance of daily journeys as a consequence of an uncontrolled urban growth, etc. For example, in the UK, it has been estimated that to maintain traffic congestion at the current level means multiplying by five annual investments in road building or increasing five times fuel taxation [40].

Adjusting the excessive growth of the car fleet in a small and highly populated region as the Basque Country meant turning a great amount of natural land into artificial land, both for mobility purposes and for parking space. The increase of registered vehicles in the last 15 years requires a parking surface equal to the construction of 19 tracks in the highway that links Bilbao with Donostia (around $100 \mathrm{~km}$ ) [33].

The depletion of natural resources due to transport is not only owed to land consumption but also to its huge consumption of energy. Between 1990 and 2004, the transport has shifted from representing $22 \%$ of final energy consumed in the Basque Country to $31 \%$, being road transport responsible for $95 \%$ of that consumption. Transport depends almost exclusively on oil at a time where the proximity of the peak-oil foresees a significant rise of crude oil price [26]. In real terms, the current price of the oil barrel is four times higher than in 1998.

Transport is also the cause of numerous social and environmental adverse effects. First, transport has remarkable impacts on the consumption of natural resources (mainly land, materials and energy). Second, the fragmentation of the habitat contributes significantly to the loss of biodiversity and landscape degradation. The surface of sensitive areas less than $500 \mathrm{~m}$ away from great road infrastructures reaches 6\% [41]. Extrapolating the results from studies carried out in other regions, half of the Basque Country could be ecologically affected by transport infrastructures [42].

Finally, regarding the emissions into the atmosphere, despite the reduction in some pollutant emissions, transport has increased its share of total emissions and it is the main source of atmospheric pollution in urban areas [43]. Furthermore, transport is pulling away from the fulfilment of the Kyoto Protocol by the Basque Government since its greenhouse gas emissions have increased by $85 \%$ since 1990 [44]. Other contaminants, such as lead, have disappeared, and the precursors of ozone and acid-producing substances have been reduced considerably. However, the presence of polycyclic aromatic hydrocarbons like some heavy metals has increased. Transport is directly 
responsible for the emission of $15 \%$ of PM10, $54 \%$ of CO, $10 \%$ of NMVOC, $5 \%$ of SO2, $33 \%$ of NOx, $45 \%$ of the precursors of troposphere ozone and $27 \%$ of acid-producing substances [31].

In the social context, despite a slight decrease in comparison with the levels in 1980s, the rate of human lives lost with road transport is over 200 and more than 10,000 injured a year [45]. Moreover, traffic accidents are the first cause of death in the EU for people under 45 years [46]. To this dramatic registry, it can be added that the effects of pollutant emissions on human health, increasingly researched in the EU, and the results of such researches confirm that long-term exposure to polluting emissions from transport provokes twice more deaths than traffic accidents [47]. With regard to noise pollution, $18 \%$ of the Basque population is affected by unacceptable noise levels - above 65 $\mathrm{dB}(\mathrm{A})$ - produced by the road network [44]. The hegemony of road transport in the current transport system has also territorial and social implications far beyond the health effects of pollutant emissions. The hypermobility not only threatens with obstructing the arteries of the transport system but also entails urban sprawl, greater social polarization between the owners of private vehicles and those who do not own one, greater risk on the roads, greater hostility for children, obesity problems, lower cultural variety, lower social interaction of the population, an increase of crime levels and a growing lack of governance [48].

\subsection{Transport and economy}

The relation between transport and welfare is rather difficult to establish due to the fact that transport is a means for the rest of activities. It is precisely this feature - being a means for greater social welfare and not an end in itself - which makes the importance of transport, in a modern economy, rely not so much on its contribution to GDP than on its efficiency for the other activities. And, given that means are considered a cost for the economy, its reduction would contribute to greater economic efficiency. According to this, the SACTRA report, requested by the British Government to analyse the relation between transport and economy, concludes that interrupting the continuous growth of transport could benefit economy [49]. In other words, the report confirms the existence of a threshold from which transport system's hypertrophy has negative effects on economy as a whole; a threshold that industrialized countries seem to have crossed since external costs of transport are above the contribution of this sector to domestic product. This situation is also found in the Basque Country where the external costs of transport (8.6\%) almost double its contribution to GDP (4.7\%) [42]. In conclusion, to feed the growth of transport would be anti-economy, if the costs of such growth exceeded the benefits. In fact, the external costs of transport in the Basque Country are estimated to exceed 3,500 million $€$ per annum, close to $9 \%$ of the Basque GDP, being road transport alone responsible for more than $95 \%$ of such cost [31]. External costs of transport are similar to those in the EU, as Fig. 3 shows.

In sum, this section has covered the historical trends and current situation of the transport system in the Basque Country. As it is the case in many European regions, provision of new infrastructures and certain internalization of externalities strategies have not reversed past negative trends. As a consequence, symptoms of hypertrophy have appeared in the transport system: environmental damages, human health, economic losses, etc. As it has been shown, unsustainability of the system appears not only at an environmental level but also at a social and economic level.

\section{CONCLUSIONS}

The development of current modes of transport pursued the increase of speed and accessibility in journeys, especially around the image of private vehicles. However, the expansion of the transport system itself, in order to grant more speed to journeys, was the cause of the growing congestion on 

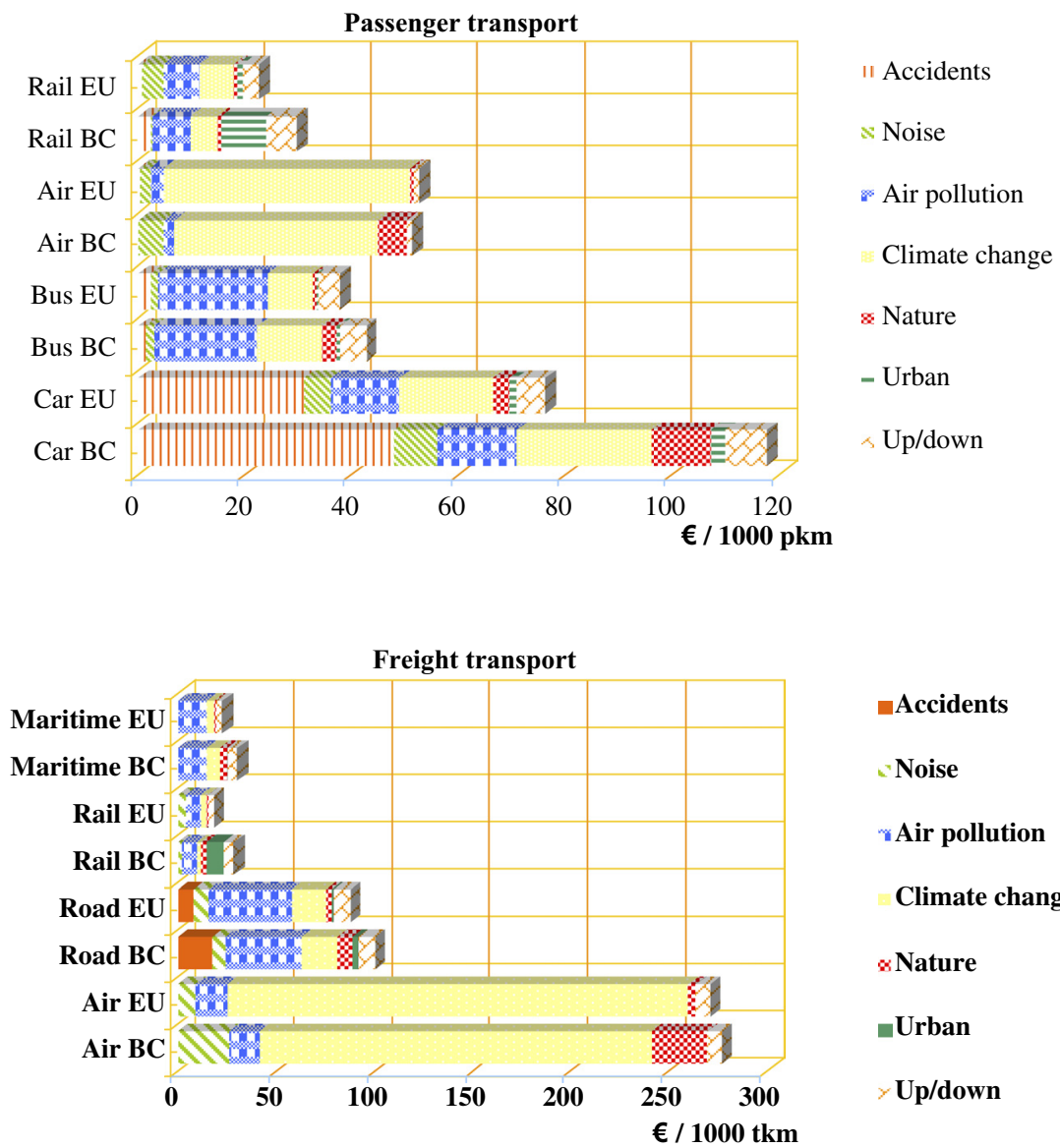

\author{
Accidents \\ Noise \\ Air pollution \\ Climate change \\ sNature \\ -Urban \\ Up/down
}

Figure 3: External costs of transport in the Basque Country compared to EU [31].

the roads, which reduced dramatically the expected speed and accessibility, apart from causing other economic, environmental and social effects. Thus, taking the Basque Country as an example, external costs of transport, estimated at $8.6 \%$ of the annual GDP, largely exceed the contribution of this sector to the GDP (4.7\%). Given the apparent symptoms of hypertrophy in the transport system, it is anti-economic to feed transport growth even more. Consequently, the agreement is greater regarding the fact that not only transport efficiency but also the whole economy depends on the reduction of the continuous growth of transport.

Among the several instruments existing with the purpose of reverting this situation (economic, technical, institutional, demand management, etc.), economists usually prefer price measures. In particular, in transport economics it is considered that the optimal infrastructure pricing is the most efficient instrument for the internalization of externalities. Undoubtedly, infrastructure pricing and the establishment of urban tolls have joined theory and practice showing that these are instruments that can be and must be used for the sake of transport efficiency improvement (London, Switzerland, Germany, etc.). Nevertheless, the reviewed literature not only provokes uncertainties concerning the long-term possibilities of this instrument to stop the environmental depletion and the effects on 
health derived from the current transport model but also defends the implementation of the instrument combination. This instrument combination, in spite of deciding the correct way, insists on the traditional perspective of the transport policy, tending to find end-of-pipe solutions, which far from questioning the nature of journeys, it just rationalizes them to take advantage of the available infrastructures.

However, as stated by the European Commission [2], the 'transport problem consists of a series of interrelated problems claiming an integrated answer'. Efficiency of the transport system is a clear aim, although it is neither the only one nor the most important. The urgent environmental problems especially climate change and the depletion of the natural resources - require the urgent reconsideration of means and goals in order to advance in the transition towards transport sustainability. Alternatively, sustainable mobility - defined as a process that tends to reduce the irreversible environmental degradation of the current transport model while satisfying the social need of accessibility - has been proposed. Built as an alternative to the current mobility model based on the transport policy as the only instrument capable of answering to the multiple problems caused thereby, this new concept encloses the bases on which a transport model can be built aiming to reduce the impacts on the physical and human environment. Sustainable mobility is, thus, the implementation of the sustainability concept into the transport system.

In sum, the complexity of the challenge presented by the conciliation of transport, environment and health requires a systemic approach, where all policies with aftermaths on mobility (land planning, urbanism, energy policy, etc.) participate integrally, with special interest in the origin of the problem. While the previous paradigm offered a final image of transport, where mobility and speed were good by themselves, sustainable mobility as an operational concept requires the reduction of the environmental impacts of transport, through the fulfilment of three fundamental goals: the reduction of the need of transport, rebalancing the current modal share in favour of less pollutant means of transport and the improvement of the eco-efficiency of the journeys. In this context, the creation of proximity becomes the driving principle of the sustainable mobility policy, while instruments that used to be out of the transport policy acquire special significance; for instance, land planning, urbanism and the amendment of current production and consumption patterns.

\section{ACKNOWLEDGEMENTS}

The author acknowledges the financial support from the Department of Environment of the Basque Government and IHOBE, S.A, and from the Department of Education of the Basque Government through grant IT-334-07 (UPV/EHU Econometrics Research Group). I would also like to thank David Guillamon, Roberto Bermejo and two anonymous referees for providing remarks on earlier drafts that considerably improved the paper. Full responsibility of errors remains with the author.

\section{REFERENCES}

[1] INFRAS/IWW, External Costs of Transport. Accidents, Environment and Congestion Costs in Western Europe, UIC, Zurich/Karlsruhe, 2000.

[2] European Commission, Towards Fair and Efficient Pricing in Transport Policy. Policy Options for Internalising the External Cost of Transport in the European Union, Green Paper, COM (95) 691 final, 20 December 1995.

[3] European Commission, Proposal for a Directive of the European Parliament and of the Council by which directive 1999/62/EC on charging heavy goods vehicles for the use of certain infrastructures, 23 July 2004.

[4] SACTRA, Trunk Road and the Generation of Traffic, Standing Advisory Committee for Trunk Road Assessment (SACTRA), HMSO, London, 1999. 
[5] Cairns, S., Hass-Klau, C. \& Goodwin, P., Traffic Impact of Highway Capacity Reductions: Assessment of the Evidence, Landor Publishing: London, 1998.

[6] INFRAS/IWW, External Effects of Transport, UIC, Zurich/Karlsruhe, 1995.

[7] INFRAS/IWW External Costs of Transport. Update Study, UIC, Zurich/Karlsruhe, 2004.

[8] OECD, External Costs of Transport in Central and Eastern Europe, Working Party on National Environmental Policy, Working Group on Transport. WNV/EPOC/WPNEP/ $\mathrm{T}(2002) 5 /$ FINAL.

[9] JEGTE, Recommendations for Action Towards Sustainable Transport. A Strategy Review, European Commission, Joint Expert Group on Transport and Environment, 2001.

[10] European Commission, Fair Payment for Infrastructure Use: A Phased Approach to a Common Transport Infrastructure Charging Framework in the EU, White paper, COM (1998) 466 final, Brussels, 1998.

[11] European Commission, European Transport Policy for 2010: Time to Decide, White paper, COM (2001) 370 final, Brussels, 2001.

[12] Nash, C., Sansom, T. \& Still, B., Modifying transport prices to internalise externalities: evidence from European case studies. Regional Science and Urban Economics, 31(4), pp. 413-431, 2001.

[13] De Rus, G., Campos, J., \& Nombela, G., Economía del transporte, Antoni Bosch: Barcelona, 2003.

[14] De Borger, B. \& Proost, S., Reforming Transport Pricing in the European Union: a Modelling Approach, Edward Elgar: Cheltenham, 2001.

[15] Gaunt, M., Rye, T., \& Allen, S., Public acceptability of road user charging: the case of Edinburgh and the 2005 Referendum. Transport Reviews, 27(1), pp. 85-102, January 2007.

[16] O.I. Larsen \& K. Ostmoe, The experience of urban toll cordons in Norway: lessons for the future. Journal of Transport Economics and Policy, 35(3), pp. 457-471, 2001.

[17] Laird, J.J., Nash, C.A., Nellthorp, J., Macário, R., Van der Hoofd, M., Carmona, M., Proost, S., Suter, S. \& Lieb, C., Deliverable 1. State of the Art and Conceptual Background, REVENUE, Revenue Use from Transport Pricing, Project Funded by European Commission - DG TREN Fifth Framework Programme, 2004.

[18] Beuthe, M., Degrandsart, F., Geerts, J.F. \& Jourquin, B., External costs of the Belgian interurban freight traffic: analysis of their internalisation, Transportation Research Part D, Transport and Environment, 7(4), pp. 285-301, 2002.

[19] Nash, C. \& Sansom, T., Pricing European transport systems. Recent developments and evidence from case studies. Journal of Transport Economics and Policy, 35(3), pp. 363-380, 2001.s

[20] Suter, S. \& Walter, F., Environmental pricing - theory and practice. The Swiss Policy of heavy vehicle taxation. Journal of Transport Economics and Policy, 35(3), pp. 381-397, 2001.

[21] Rothengatter, W., External costs and ways of internalisation. SOFTICE (Survey on Freight Transport Including Cost Comparison in Europe), Funded by the 4th Framework RTD Programme, 1998.

[22] OECD, Environmentally Sustainable Transport. Guidelines, http://www.oecd.org/dataoecd/53/ 21/2346679.pdf?channelId=34363yhomeChannelId=33713yfileTitle=EST+Guidelines, 2000.

[23] UIC, Internalisation of external costs: instruments, International Union of Railways (UIC), Paris, Policy Paper 01/1999, 1999.

[24] Gudmundsson, H., Mobility as a policy concept. Social Perspectives on Mobility, eds T. Thomsen, L. Drewes \& H., Gudmundsson, Ashgate, 2005.

[25] OECD, Road Travel Demand. Meeting the challenge, OECD: Paris, 2002. 
[26] Bermejo, R., The Great Transition to Sustainability: Principles and Strategies for a Sustainable Economy, Los Libros de la Catarata: Madrid, 2005.

[27] Richard, G., Sustainable mobility in the city. Centre for Sustainable Transportation, URBAN 21, Global Conference on the Urban Future, Berlin, July 4-6, 2000.

[28] Eliasson, J. \& Mattson, L., Transport and location effects of road pricing: a simulation approach. Journal of Transport Economics and Policy, 35(3), pp. 417-456, 2001.

[29] Spanish Ministry of Public Works, Annual Statistics, Madrid, 2004.

[30] INE, Spanish Statistics Office, www.ine.es.

[31] Basque Government, MUGIKOST 2005. External Costs of Transport in the Basque Country, IHOBE, S.A.: Bilbao, 2005.

[32] DG TREN, Energy and Transport in Figures 2006, European Commission, DirectorateGeneral for Energy and Transport, 2006.

[33] Basque Government, Transport and Environment in the Basque Country. TMA Indicators 2002, IHOBE, S.A.: Bilbao, 2002.

[34] EUSTAT, Basque Statistics Office, www.eustat.es.

[35] PCB, Evolution of Road Traffic in Bizkaia 2001, Provincial Council of Bizkaia, Public Works and Transport Department, Bilbao, 2002.

[36] Basque Government, Final Image of Transport in the Basque Country, Bilbao, 2003.

[37] PCB, Evolution of Road Traffic in Bizkaia 2004, Provincial Council of Bizkaia, Public Works and Transport Department, Bilbao, 2005.

[38] PCA, Road Capacity Plan in Alava, Provincial County of Alava, Public Works and Transport Department, Vitoria-Gasteiz, 2002.

[39] PCG, Information on Road Capacity in Gipuzkoa, Provincial County of Gipuzkoa, Public Works and Transport Department, Donostia-San Sebastian, 2002.

[40] RAC, Motoring Towards 2050, RAC Foundation: London, 2002.

[41] Rosell, C., Álvarez, G., Cahill, C., Campeny, C., Rodriguez, A. \& Seiler, A., Cost 341. Habitat Fragmentation in Relation to Transport Infrastructures in Spain, Spanish Environment Ministry, Madrid, 2003.

[42] Hoyos, D., The estimation of external costs of transport: the case of the Basque Country. Ekonomiaz, 57(4), pp. 240-267, 2005.

[43] EEA, Emissions of Atmospheric Pollutants in Europe 1990-1999, Topic report, European Environmental Agency, Copenhague, 2002.

[44] Basque Government, Environment in the Basque Country. Environmental Indicators 2004, IHOBE, S.A.: Bilbao, 2004.

[45] Spanish Home Office, Accidents Yearbook, General Directorate for Traffic, Madrid, 2004.

[46] EEA, Europe's Environment: The Third Assessment, European Environmental Agency, Copenhagen, 2003.

[47] WHO, Health Costs due to Road Traffic-related Air Pollution. An Impact Assessment Project of Austria, France and Switzerland, World Health Organization, Synthesis report, prepared for the WHO Ministerial Conference on Environment and Health, London, 1999.

[48] Adams, J., Hypermobility: a challenge to governance. New Modes of Governance: Developing an Integrated Policy Approach to Science, Technology, Risk and the Environment, eds C. Lyall \& J. Tait, Ashgate: Aldershot, 2005.

[49] SACTRA, Transport and the Economy, Standing Advisory Committee for Trunk Road Assessment (SACTRA), HMSO, London, 1999. 